\title{
Arbeidsparticipatie van arbeidsgehandicapten, resultaten uit de arbeidsgehandicaptenmonitor van het $\mathrm{CBS}$
}

\author{
J.J.M. Besseling, F.C. Verboon
}

\section{Samenvatting}

Sinds 2000 zijn in de Enquête Beroepsbevolking van het CBS vragen opgenomen om de arbeidsparticipatie van arbeidsgehandicapten te monitoren.

Van de personen van 15 tot 65 jaar achtte in 2000 zich $13,6 \%$ arbeidsgehandicapt en dat is gestegen tot $14,7 \%$ in 2002 . Van de mannen is in de periode $2000-2002$ ongeveer $13,9 \%$ arbeidsgehandicapt terwijl het percentage onder vrouwen is gestegen van $13,4 \%$ naar $15,6 \%$. Ouderen achten zich veel vaker arbeidsgehandicapt dan jongeren. In elke leeftijdscategorie is het percentage arbeidsgehandicapten toegenomen van 2000 naar 2002. Laagopgeleiden zijn twee maal zo vaak arbeidsgehandicapt dan hoogopgeleiden. Van de werkzame beroepsbevolking is in $200210,9 \%$ arbeidsgehandicapt en van de niet-beroepsbevolking $23 \%$.

Van de werkzame arbeidsgehandicapten geeft $30 \%$ aan dat er in de voorafgaande periode van 12 maanden een aanpassing is gerealiseerd en $16 \%$ geeft aan een aanpassing nodig te hebben. Van de werknemers in het openbaar bestuur zijn relatief weinig personen arbeidsgehandicapt (9\%) maar een groot deel hiervan (36\%) heeft een aanpassing ontvangen in de afgelopen 12 maanden.

In de discussie worden enkele trends besproken en worden de resultaten van de CBS-monitor vergeleken met die van UWV.

Trefwoorden: arbeidsparticipatie, aanpassingen, aandoeningen, arbeidsgehandicaptenmonitor, CBS

\section{Inleiding}

De overheid neemt maatregelen om mensen met gezondheidsproblemen meer te integreren in de arbeidsmarkt. Om de effectiviteit van dit beleid vast te stellen heeft het Centraal Bureau voor de Statistiek (CBS) op verzoek van het ministerie van SZW sinds april 2000 enkele vragen in de Enquête Beroepsbevolking (EBB) opgenomen om de arbeidssituatie van arbeidsgehandicapten te monitoren.

De Monitor Arbeidsgehandicapten heeft twee hoofddoelen. Het eerste doel is na te gaan hoeveel mensen met een langdurige ziekte, aandoening of handicap (verder slechts aangeduid als langdurige aandoening) hier- door belemmerd worden in het uitoefenen of het vinden van werk, de zogeheten arbeidsgehandicapten, en deze groep te monitoren. Deze afbakening van het begrip arbeidsgehandicapte sluit grotendeels aan bij de formulering van de Wet Rea, al ontbreekt een expliciete verwijzing naar het (hebben) ontvangen van een arbeidsongeschiktheidsuitkering of voorziening en/of het sociaal medisch oordeel. ${ }^{1}$

Een tweede hoofddoel is het beantwoorden van de vraag welke maatregelen naar de mening van de geïnterviewden getroffen zijn ter preventie van uitval uit het werk en/of reïntegratie en hoe het treffen van deze maatregelen zich in de tijd ontwikkelt.

- Vrouwen zijn vaker arbeidsgehandicapt dan mannen.

- Er is sprake van een toename van gerealiseerde aanpassingen voor werkende arbeidsgehandicapten.

- Er is een onverklaarbaar verschil in arbeidsparticipatie van arbeidsgehandicapten tussen CBSen UWV-monitor.

- In het openbaar bestuur zijn weinig werkende arbeidsgehandicapten maar wel veel aanpassingen. 
Tabel 1

Personen van 15-64 jaar naar langdurige aandoening en arbeidshandicap

\begin{tabular}{lrrr}
\hline & \multicolumn{3}{c}{ Aantal $\times 1.000$} \\
\cline { 2 - 4 } & 2000 & 2001 & 2002 \\
\hline Totaal bevolking 15-64 jaar & 10.723 & 10.801 & 10.871 \\
Waarvan met langdurige & & & \\
$\quad$ aandoening & 2.513 & 2.568 & 2.631 \\
Waarvan arbeidsgehandicapt & 1.455 & 1.512 & 1.602 \\
Percentage arbeidsgehandicapten & $13,6 \%$ & $14,0 \%$ & $14,7 \%$ \\
\hline
\end{tabular}

Onlangs zijn de resultaten over 2002 beschikbaar gekomen op de website van het $\mathrm{CBS}^{2}$ (zie ook kader) en binnenkort verschijnt naar verwachting ook een rapportage over de Arbeidsgehandicaptenmonitor 2002 op papier. ${ }^{3}$ In dit artikel geven we vanuit een epidemiologische invalshoek een schets van de arbeidsgehandicapten in 2002, de gerealiseerde aanpassingen en de behoefte aan aanpassingen bij werkzame arbeidsgehandicapten (zie kader op pagina 110). Epidemiologisch betekent in dit verband dat we aangeven hoe groot de kans is dat iemand met een bepaald kenmerk arbeidsgehandicapt is.

We stippen trends aan die zichtbaar zijn over de periode 2000-2002 en in de discussie gaan we in op verklaringen voor deze trends. Ook plaatsen we deze bevindingen naast de bevindingen van de arbeidsgehandicaptenmonitor van UWV.

\section{Schets van de arbeidsgehandicapten}

In 2002 telde het CBS in Nederland bijna 10,9 miljoen personen van 15 tot 65 jaar. Daarvan geven 2,6 miljoen personen aan dat ze een langdurige aandoening hebben en 1,6 miljoen personen worden door die aandoening beperkt in het verkrijgen van werk of het uitvoeren van hun werk. Van de potentiële beroepsbevolking is in $200214,7 \%$ arbeidsgehandicapt (zie tabel 1).
Toename van arbeidsgehandicapte vrouwen

Over de periode $2000-2002$ is de potentiële beroepsbevolking enigszins toegenomen $(1,4 \%)$. Ook het aantal personen met een langdurige aandoening is toegenomen. Deze toename is echter beduidend sterker namelijk $4,7 \%$. Wat niet uit de tabel blijkt, is dat een steeds groter deel van de personen met een langdurige aandoening arbeidsgehandicapt is $(57,9 \%$ in 2000 naar $60,9 \%$ in 2002$)$. Het resultaat is een sterke toename van het deel van de beroepsbevolking dat arbeidsgehandicapt is $(13,6 \%$ in 2000 naar $14,7 \%$ in 2002).

In tabel 2 geven we een typering van de incidentie van het arbeidsgehandicapt zijn. Niet alle groepen hebben dezelfde kans om arbeidsgehandicapt te zijn. Vrouwen zijn bijvoorbeeld vaker arbeidsgehandicapt dan mannen. In 2002 is $15,6 \%$ van de vrouwen arbeidsgehandicapt tegenover $13,9 \%$ van de mannen. Het percentage arbeidsgehandicapten is bij mannen over de periode 2000-2002 constant gebleven, terwijl het percentage bij vrouwen vanaf 2000 sterk is gestegen vanaf een niveau iets onder dat van de mannen $(13,4 \%)$ naar een beduidend hoger percentage.

Ouderen zijn veel vaker arbeidsgehandicapt dan jongeren. Onder de 25 jaar is 'slechts' 5,4\% arbeidsgehandicapt, van de 55- tot 65-jarigen is ruim een kwart arbeidsgehandicapt. Over de periode 2000-2002 is er sprake van twee ontwikkelingen.

De eerste ontwikkeling is dat de bevolking vergrijst. De groep van 25- tot 34 -jarigen is niet alleen relatief gedaald in omvang maar ook absoluut van 2.440 duizend in 2000 naar 2.343 in 2002 . Het zijn met name de oudere leeftijdsgroepen die zowel relatief als absoluut in omvang zijn toegenomen.

De tweede ontwikkeling is dat in elke leeftijdsgroep een toenemend percentage personen arbeidsgehandicapt is. Deze stijging is het grootst in zowel de jongste leeftijdsgroep (van $4,4 \%$ naar $5,4 \%$ ) als in de oudste leef-

Tabel 2

Personen van 15-64 jaar naar kenmerk en percentage arbeidsgehandicapten, 2000-2002

\begin{tabular}{|c|c|c|c|c|c|c|}
\hline & \multicolumn{3}{|c|}{ Aantal $\times 1000$} & \multicolumn{3}{|c|}{ Waarvan arbeidsgehandicapt in \% } \\
\hline & 2000 & 2001 & 2002 & 2000 & 2001 & 2002 \\
\hline Totaal & 10.723 & 10.801 & 10.871 & 13,6 & 14,0 & 14,7 \\
\hline \multicolumn{7}{|l|}{ Geslacht } \\
\hline Man & 5.431 & 5.469 & 5.502 & 13,8 & 13,8 & 13,9 \\
\hline Vrouw & 5.292 & 5.332 & 5.368 & 13,4 & 14,2 & 15,6 \\
\hline \multicolumn{7}{|l|}{ Leeftijd } \\
\hline $15-24$ jaar & 1.860 & 1.883 & 1.892 & 4,4 & 4,8 & 5,4 \\
\hline $25-34$ jaar & 2.440 & 2.396 & 2.343 & 9,4 & 9,4 & 10,2 \\
\hline $35-44$ jaar & 2.538 & 2.565 & 2.599 & 13,1 & 13,2 & 13,5 \\
\hline $45-54$ jaar & 2.286 & 2.331 & 2.376 & 19,7 & 20,6 & 20,3 \\
\hline 55-64 jaar & 1.600 & 1.625 & 1.660 & 22,5 & 23,2 & 25,7 \\
\hline \multicolumn{7}{|l|}{ Opleiding } \\
\hline Lager opgeleid & 4.128 & 4.153 & 4.048 & 17,5 & 18,0 & 19,5 \\
\hline Middelbaar opgeleid & 4.217 & 4.260 & 4.267 & 12,1 & 12,7 & 13,2 \\
\hline Hoger opgeleid & 2.371 & 2.382 & 2.545 & 9,3 & 9,4 & 9,7 \\
\hline
\end{tabular}


Tabel 3

Personen van 15-64 jaar met een langdurige aandoening, naar arbeidshandicap en type aandoening, 2000-2002

\begin{tabular}{|c|c|c|c|c|c|c|}
\hline & \multicolumn{3}{|c|}{ Aantal personen met langdurige aandoening $\times 1.000$} & \multicolumn{3}{|c|}{ Waarvan arbeidsgehandicapt (\%) } \\
\hline & 2000 & 2001 & 2002 & 2000 & 2001 & 2002 \\
\hline Totaal & $2.513^{\star}$ & 2.568 & 2.631 & 57,9 & 58,9 & 60,9 \\
\hline Rug- en gewrichtsklachten & 1.357 & 1.362 & - & 66,7 & 67,8 & - \\
\hline Armen & - & - & 699 & - & - & 76,7 \\
\hline Benen & - & - & 772 & - & - & 74,5 \\
\hline Rug- en nekklachten & - & - & 1.188 & - & - & 72,6 \\
\hline Migraine of ernstige hoofdpijn & 406 & 427 & 467 & 68,9 & 70,0 & 74,3 \\
\hline Hart- of vaatziekten & 267 & 309 & 310 & 62,7 & 61,2 & 67,1 \\
\hline Bronchitis, asthma of CARA & 427 & 412 & 437 & 48,3 & 49,6 & 51,8 \\
\hline Maag- of darmstoornissen & 295 & 282 & 288 & 67,3 & 70,0 & 69,5 \\
\hline Suikerziekte & 162 & 172 & 174 & 48,6 & 53,1 & 52,7 \\
\hline Ernstige huidziekte & 105 & 115 & 101 & 58,2 & 55,3 & 59,0 \\
\hline Psychische klachten & 415 & 424 & 447 & 79,1 & 81,0 & 80,0 \\
\hline Gehoorproblemen & 207 & 196 & 197 & 60,1 & 61,4 & 68,6 \\
\hline Epilepsie & - & - & 36 & - & - & 100,0 \\
\hline Progressieve ziekten & - & - & 102 & - & - & 78,1 \\
\hline Andere aandoening & 354 & 373 & 206 & 48,7 & 50,0 & 43,0 \\
\hline
\end{tabular}

ॠ Mensen kunnen meerdere aandoeningen hebben

- Gegevens niet beschikbaar.

tijdsgroep (van $22,5 \%$ naar $25,7 \%$ ). Dat betekent dat de vergrijzing slechts deels een verklaring is voor de stijging van het aantal arbeidsgehandicapten.

\section{Laagopgeleiden zijn vaker arbeidsgehandicapt}

Opleidingsniveau en arbeidshandicap hangen sterk samen. Lager opgeleiden zijn twee maal zo vaak arbeidsgehandicapt als hoger opgeleiden. Uit de beschikbare gegevens kan niet worden achterhaald in welke mate lager opgeleiden vaker een langdurige aandoening krijgen en vervolgens vaker arbeidsgehandicapt zijn dan wel door hun langdurige aandoening weinig scholing hebben kunnen volgen.

Over de periode $2000-2002$ is binnen alle drie de opleidingsniveaus sprake van een toename van het percentage arbeidsgehandicapten, al is de toename onder laagopgeleiden zowel absoluut als relatief het grootst geweest (van $17,5 \%$ naar $19,5 \%$ ).

Relatie tussen aandoeningen en arbeidsgehandicapt zijn

Een voorwaarde voor het arbeidsgehandicapt zijn, is dat men een langdurige aandoening heeft. In tabel 3 geven we een overzicht van de langdurige aandoeningen die men genoemd heeft en de relatie met het arbeidsgehandicapt zijn. De meest genoemde aandoeningen betreffen rug- en nekklachten (meer dan een miljoen maal genoemd), benen en armen. Andere veel voorkomende aandoeningen zijn migraine of ernstige hoofdpijn, psychische klachten en 'bronchitis, astma en cara' ieder ongeveer 450 duizend maal genoemd.

Alle personen met epilepsie geven aan dat ze arbeidsgehandicapt zijn. Personen met psychische klachten zijn ook relatief vaak ar- beidsgehandicapt, namelijk $80 \%$. Dit percentage is constant over de afgelopen 3 jaren. We hebben geen trend kunnen vaststellen tussen aandoeningen en het arbeidsgehandicapt zijn. Het vaststellen van een trend wordt ook enigszins belemmerd doordat het CBS in de EBB van 2002 de rug- en gewrichtsklachten nader heeft onderscheiden in genoemde driedeling en enkele aandoeningen (epilepsie en progressieve ziekten) heeft toegevoegd.

Arbeidsgehandicapten vaker buiten arbeidsproces

In 2002 zijn, zoals we ook zagen in tabel 1, ruim 1,6 miljoen mensen van 15-64 jaar door een langdurige aandoening, ziekte of handicap belemmerd in het verkrijgen van werk of uitvoeren van hun werk; de arbeidsgehandicapten. Dit zijn er iets meer dan in 2001 en in 2000.

Uit tabel 4 blijkt dat in 2002 bijna 820 duizend arbeidsgehandicapten behoren tot de beroepsbevolking waarvan 778 duizend werkzaam zijn en 40 duizend werkloos. Daarnaast geven bijna 120 duizend arbeidsgehandicapten die niet tot de beroepsbevolking behoren aan werk van 12 uur of meer per week te willen hebben. De overige 575 duizend arbeidsgehandicapten geven aan niet te kunnen of te willen werken. De arbeidsdeelname van arbeidsgehandicapten is aanzienlijk lager dan die van de totale bevolking van 15-64 jaar. Dat blijkt uit de laatste kolom van tabel 4 .

Van de werkzame beroepsbevolking is 10,9\% arbeidsgehandicapt. Van de werkloze beroepsbevolking is $12,3 \%$ arbeidsgehandicapt. Van de niet-beroepsbevolking is bijna twee maal zoveel arbeidsgehandicapt namelijk $23 \%$. Wat betreft de categorieën buiten de beroepsbevolking geeft een relatief groot deel van de arbeidsgehandicapten aan niet te kun- 
Tabel 4

Personen van 15-64 jaar naar arbeidshandicap en arbeidspositie, 2002

\begin{tabular}{lrcc} 
& Total & $\begin{array}{l}\text { Arbeids- } \\
\text { gehandicapt }\end{array}$ & \\
& $\times 1.000$ & $\times 1.000$ & $\%$ \\
\hline Totaal & 10.871 & 1.602 & 14,7 \\
Beroepsbevolking & 7.444 & 815 & 11,0 \\
$\quad$ Werkzaam & 7.141 & 778 & 10,9 \\
Werkloos & 302 & 37 & 12,3 \\
Niet beroepsbevolking & 3.427 & 787 & 23,0 \\
$\quad$ Wil wel 12 uur/week of meer werken & 393 & 91 & 23,1 \\
Kan niet werken & 461 & 302 & 65,5 \\
Wil niet 12 uur/week of meer werken & 2.573 & 394 & 15,3 \\
\hline
\end{tabular}

nen werken. Echter, ook onder degenen die aangeven dat ze wel werk van 12 uur of meer per week zouden willen hebben bevinden zich veel arbeidsgehandicapten namelijk $23 \%$. Deze cijfers zijn vrij sterk veranderd van 2001 naar 2002. Zo is het percentage arbeidsgehandicapten gedaald onder de werkloze beroepsbevolking van $16 \%$ naar ruim $12 \%$. Bekend is echter dat arbeidsgehandicapten langer werkloos blijven. ${ }^{4}$ De daling wordt waarschijnlijk veroorzaakt door de sterke toename van de werkloosheid waaronder vooral relatief veel jongeren en dus weinig arbeidsgehandicapten zijn. De niet-beroepsbevolking bestaat juist voor een steeds groter deel uit arbeidsgehandicapten (van $18,7 \%$ in 2000 naar $23,0 \%$ in 2002 ).

\section{Helft heeft geen aanpassing (meer) nodig}

Eén van de maatregelen die kan worden ingezet om de arbeidsparticipatie van arbeidsgehandicapten te verhogen is het aanpassen van de werkplek of de werkzaamheden. In 2002 geeft iets meer dan de helft van de werkende arbeidsgehandicapten aan dat geen verdere aanpassingen nodig zijn ten aanzien van de werkplek of de werkzaamheden (tabel 5). Daarnaast geeft $30 \%$ van hen aan een aanpassing gehad te hebben in de afgelopen 12 maanden en $16 \%$ geeft aan een aanpassing nodig te hebben om goed te kunnen functioneren. Werkzame vrouwelijke arbeidsgehandicapten hebben ongeveer even vaak een aanpassing gekregen als mannen (respectievelijk $30 \%$ en $29 \%$ ) en ze geven ook ongeveer even vaak aan dat een aanpassing nodig is.

De gerealiseerde aanpassingen betreffen blijkens tabel 6 vooral hulpmiddelen of meubilair en aanpassingen aan functie of takenpakket. Vrouwelijke werkzame arbeidsgehan- dicapten melden vaker dan mannen een aanpassing aan hulpmiddel of meubilair en aan werktijden. Bij mannen is iets vaker sprake van aanpassing van de functie of het takenpakket.

In openbaar bestuur weinig arbeidsgehandicapten, veel aanpassingen

Op globaal niveau geeft de monitor ook branche-informatie over het arbobeleid (tabel 7). Enerzijds geeft de monitor informatie over het aantal werkzame arbeidsgehandicapten in branches, anderzijds geeft de monitor informatie over gerealiseerde aanpassingen en benodigde aanpassingen bij werkzame arbeidsgehandicapten per branche.

De werknemers in de industrie beschouwen zich het vaakst als arbeidsgehandicapt: $14 \%$ geeft aan dat ze door een langdurige aandoening belemmerd zijn in het verkrijgen of behouden van werk. Werknemers bij financiële instellingen, zakelijke dienstverlening en openbaar bestuur zijn het minst vaak arbeidsgehandicapt (9\%). Voor de werkzame arbeidsgehandicapten in het openbaar bestuur is het vaakst een aanpassing gerealiseerd in de voorafgaande 12 maanden (36\%) en voor die in de bouwnijverheid het minst. Overigens betekent dat niet dat er daar te weinig aanpassingen worden gerealiseerd aangezien men in de bouwnijverheid iets minder vaak dan gemiddeld aangeeft dat een aanpassing nodig is. Werkzame arbeidsgehandicapten in het onderwijs hebben het vaakst behoefte aan aanpassingen. Overigens hebben met name de cijfers over de aanpassingen een relatief grote onzekerheidsmarge doordat de gegevens vanuit relatief kleine groepen zijn geëxtrapoleerd.

Ook in 2001 werd in het openbaar bestuur voor de werkzame arbeidsgehandicapten het vaakst een aanpassing gerealiseerd. De bouwnijverheid behoorde in 2001 tot de hekkensluiters bij het realiseren van aanpassingen en in het onderwijs hadden de werkzame arbeidsgehandicapten meer dan gemiddeld aanpassingen nodig.

\section{Discussie}

Het CBS heeft voor het derde achtereenvolgende jaar de arbeidsgehandicaptenmodule afgenomen als onderdeel van de jaarlijkse $\mathrm{EBB}$. Op basis van de antwoorden is vastgesteld of er sprake is van een langdurige aandoening en belemmeringen in het verrichten

Tabel 5

Werkzame arbeidsgehandicapten, naar aanpassingen en geslacht, 2002

\begin{tabular}{lccccc}
\hline & Totaal $\times \mathbf{1 . 0 0 0}$ & \% & Aanpassing gedaan* (\%) & Aanpassing nodig (\%) & Geen aanpassing nodig (\%) \\
\hline Totaal & 778 & 100 & 30 & 16 & 54 \\
Man & 434 & 100 & 29 & 16 & 55 \\
Vrouw & 344 & 100 & 30 & 17 & 52 \\
\hline
\end{tabular}

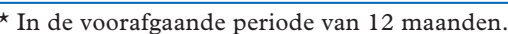


Tabel 6

Werkzame arbeidsgehandicapten naar geslacht en gerealiseerde aanpassingen in de afgelopen 12 maanden, 2002

\begin{tabular}{|c|c|c|c|c|c|c|c|}
\hline & \multicolumn{2}{|c|}{ Totaal aanpassingen gedaan } & \multirow{2}{*}{$\begin{array}{l}\text { Hulpmiddelen } \\
\text { of meubilair (\%) }\end{array}$} & \multirow[t]{2}{*}{ Werktijden (\%) } & \multirow{2}{*}{$\begin{array}{l}\text { Hoeveelheid } \\
\text { werk (\%) }\end{array}$} & \multirow{2}{*}{$\begin{array}{l}\text { Functie of } \\
\text { takenpakket (\%) }\end{array}$} & \multirow[t]{2}{*}{ Anders (\%) } \\
\hline & $\times 1.000$ & $\%$ & & & & & \\
\hline Totaal & 231 & 100 & $42^{\star}$ & 28 & 25 & 41 & 12 \\
\hline Man & 126 & 100 & 38 & 23 & 24 & 43 & 12 \\
\hline Vrouw & 105 & 100 & 47 & 33 & 25 & 38 & 11 \\
\hline
\end{tabular}

^Percentages tellen niet op tot 100 omdat meerdere aanpassingen gerealiseerd kunnen zijn.

of verwerven van arbeid. Beschouwing van de antwoorden geeft aan dat de resultaten zeer plausibel zijn: Ouderen zijn veel vaker arbeidsgehandicapt dan jongeren, vrouwen zijn iets vaker arbeidsgehandicapt dan mannen, arbeidsgehandicapten zijn vaker lager opgeleid, en de arbeidsparticipatie van arbeidsgehandicapten ligt beduidend lager.

\section{Toename onder vrouwen is verontrustend}

De resultaten van de arbeidsgehandicaptenmonitor over de jaren 2000, 2001 en 2002 illustreren enkele trends. Zo is er een toename van 2000 naar 2002 van zowel het aantal personen met een langdurige aandoening als van het deel daarvan dat arbeidsgehandicapt is. Het resultaat is dat in 2002 een groter deel van de beroepsbevolking arbeidsgehandicapt is dan in 2000. Deze toename komt vooral voor rekening van vrouwen. In 2000 was eenzelfde deel van de mannen, als van de vrouwen arbeidsgehandicapt. Bij de mannen is dit percentage constant gebleven en bij de vrouwen is het beide jaren gestegen. Deze stijging lijkt niet het gevolg te zijn van vergrijzing van de bevolking aangezien in elke leeftijdsklasse het percentage arbeidsgehandicapten is toegenomen. Het aandeel arbeidsgehandicapten onder de werkzame beroepsbevolking is gelijk gebleven. De toename van het aantal arbeidsgehandicapten komt vooral voor rekening van arbeidsgehandicapten die aangeven dat ze niet kunnen werken of niet willen werken ter- wijl het aandeel dat niet werkt maar wel wil werken is gedaald. Waarschijnlijk hangt deze ontwikkeling ook samen met de toename van het arbeidsgehandicapt zijn van vrouwen. Deze ontwikkeling past in de trend van een toenemend verschil in arbeidsongeschiktheidsrisico tussen mannen en vrouwen. ${ }^{5} \mathrm{De}$ toename van het aandeel arbeidsgehandicapten onder vrouwen over deze relatief korte periode is echter verontrustend groot en verdient nader aandacht.

\section{Actiever arbobeleid}

Een andere trend is dat een toenemend percentage werkende arbeidsgehandicapten aangeeft dat er in het afgelopen jaar een aanpassing is gerealiseerd. In 2000 gaf $26 \%$ van de werkzame arbeidsgehandicapten aan dat een aanpassing is gerealiseerd en dat is gestegen tot $30 \%$ in 2002 , terwijl het percentage dat aangeeft dat een aanpassing nodig is navenant is gedaald van $19 \%$ naar $16 \%$. Deze ontwikkeling van een actiever preventief beleid op de werkplek is in lijn met de toegenomen aandacht voor het verzuim en preventie zoals dat beoogd wordt met het arboconvenantenbeleid en de Wet verbetering poortwachter. Het lijkt ook één van de inhoudelijke verklaringen voor de afname van het verzuim en WAO-instroomrisico in de afgelopen jaren. Gegevens over de afzonderlijke branches zijn wel beschikbaar maar hebben te grote onzekerheidsmarge om statistisch ver-

Tabel 7

Werkzame arbeidsgehandicapten en aanpassingen naar bedrijfstak: 2002

\begin{tabular}{|c|c|c|c|c|}
\hline & \multirow[b]{2}{*}{ Totaal } & \multirow[b]{2}{*}{ Waarvan arbeidsgehandicapt } & \multicolumn{2}{|c|}{ Werkzame arbeidsgehandicapten } \\
\hline & & & Aanpassing gedaan & Aanpassing nodig \\
\hline Totaal & 7.141 & $11 \%$ & $30 \%{ }^{\mathrm{a}}$ & $16 \%^{\mathrm{a}}$ \\
\hline Landbouw en visserij & 198 & $12 \%$ & & \\
\hline Industrie & 1.028 & $14 \%$ & $31 \%$ & $17 \%$ \\
\hline Bouwnijverheid & 474 & $11 \%$ & $23 \%$ & $15 \%$ \\
\hline Handel & 1.062 & $10 \%$ & $25 \%$ & $17 \%$ \\
\hline Horeca & 222 & $10 \%$ & & \\
\hline Vervoer en communicatie & 420 & $11 \%$ & $32 \%$ & $18 \%$ \\
\hline Financiële instellingen & 278 & $9 \%$ & & \\
\hline Zakelijke dienstverlening & 895 & $9 \%$ & $32 \%$ & $16 \%$ \\
\hline Openbaar bestuur & 551 & $9 \%$ & $36 \%$ & $14 \%$ \\
\hline Onderwijs & 486 & $11 \%$ & $29 \%$ & $19 \%$ \\
\hline Gezondheids- en welzijnszorg & 1.024 & $12 \%$ & $31 \%$ & $18 \%$ \\
\hline Cultuur en overige dienstverlening & 313 & $13 \%$ & $32 \%$ & $16 \%$ \\
\hline
\end{tabular}

${ }^{a}$ Inclusief bedrijfstakken met te weinig waarnemingen. 
antwoorde uitspraken over trends binnen branches te kunnen doen. De gegevens illustreren wel de mogelijkheid om arbo-inspanningen en werkgeversbeleid voor het bevorderen van de arbeidsparticipatie van arbeidsgehandicapten te monitoren.

Ook geeft de monitor een nadere detaillering van de arbeidsparticipatie naar branche. Uit de monitor wordt (nog) niet duidelijk hoe deze verschillen in arbeidsparticipatie tussen branches tot stand zijn gekomen en hoe deze verschillen geduid kunnen worden. Vermoedelijk hangt een hogere participatiegraad van arbeidsgehandicapten deels samen met een hoger WAO-risico in een branche. Maar mogelijk worden in sommige branches arbeidsgehandicapten minder vaak aangenomen dan in andere branches en/of vaker ontslagen en vormt dat een verklaring voor de lagere arbeidsparticipatie in die branche. $\mathrm{Zo}_{\mathrm{o}}$ lijkt het aannemelijk dat het hoge aandeel arbeidsgehandicapten in de sector cultuur en overige dienstverlening een gevolg is van een actief aanname beleid onder ander in de vorm van WIW- en ID-banen. ${ }^{6}$

De cijfers van het Centraal Bureau voor de Statistiek (CBS) zijn gratis toegankelijk via de website. Via de website kan een elektronische databank, StatLine, worden geraadpleegd. Op de openingspagina van de website van het CBS (www.cbs.nl) staat in de rechterkolom een verwijzing naar StatLine. Via deze verwijzing komt u op de openingspagina van StatLine. Er zijn vervolgens twee manieren om te zoeken, via het selectiemenu of via een zoekmachine. De zoekmachine werkt als volgt: Kies voor Zoeken. Vul in de kolom 'Zoek in StatLine naar:' het woord 'Arbeidsgehandicapten' in en druk op zoeken. U vindt dan links naar selectietabellen. Door op een link te klikken komt $u$ in een selectietabel terecht. In de meest linkse kolom staat vervolgens een icoon met gele mappen (tabel selecteren). Door op deze icoon te klikken komt $u$ weer in de StatLine-boom terecht en kunt u vervolgens uw eigen tabel selecteren.

Er is een verschil in presentatie tussen het rapport en dit artikel. In het rapport en op StatLine wordt de groep arbeidsgehandicapten beschreven op kenmerken, bijvoorbeeld dat van de 1.602 duizend arbeidsgehandicapten $52,2 \%$ vrouw en $47,8 \%$ man is. In dit artikel beschrijven we 'het risico' op arbeidsgehandicapt zijn: voor het voorbeeld van mannen en vrouwen geldt dan dat van de 5.368 duizend vrouwen in de bevolking van 15 tot en met 64 jaar $15,6 \%$ arbeidsgehandicapt is en van de 5.502 duizend mannen is $13,9 \%$ arbeidsgehandicapt.
Vergelijking opzet $C B S$ - en $U W V$-monitor

Tot slot willen we kort de arbeidsgehandicaptenmonitor van het CBS vergelijken met die van UWV. ${ }^{7}$ De meest recente publicatie van UWV betreft cijfers over het jaar 2001. De arbeidsgehandicaptenmonitor van het CBS telt over 2001 1,5 miljoen arbeidsgehandicapten en UWV bijna 1,3 miljoen. Het bereik van de CBS-monitor is de totale potentiële beroepsbevolking en groter dan die van UWV die de arbeidsgehandicapten telt op formele wijze vanuit haar uitvoeringsfunctie van de sociale zekerheid, waardoor veel personen die arbeidsgehandicapt zijn, zoals huisvrouwen en bijstandsgerechtigden, buiten hun blikveld vallen.

De opzet van beide monitoren is zeer verschillend. De monitor van UWV is gebaseerd op de bestaande registraties van UWV en volgt de formele definitie van de arbeidsgehandicapte. Voor alle personen die een verzekerde of uitkeringsrelatie hebben met UWV, kan UWV vaststellen of er sprake is van arbeidsgehandicapt-zijn volgens de criteria van de Wet Rea en of er sprake is van arbeidsparticipatie. De informatie van de monitor komt tot nu toe relatief laat beschikbaar voor publicatie, maar aangegeven is dat de publicatie over 2002 in voorbereiding is. Over dat deel van de potentiële beroepsbevolking dat geen relatie met UWV heeft (gehad) zoals bijstandsgerechtigden ontbreekt informatie. Enerzijds is het een kracht van de UWV-monitor dat de registratie aansluit bij de wettelijke definitie, anderzijds vormt dit ook een beperking. Als de uitvoering namelijk wijzigt, bijvoorbeeld door het verlengen van de wachttijd van de WAO tot 2 jaar of de invoering van een nieuwe WAO voor duurzame volledig arbeidsongeschikten zoals het kabinet voornemens is, dan verandert de aard en inhoud van de registratie. Dit leidt tot een trendbreuk in de UWV-monitor. Indien het wettelijke begrip arbeidsgehandicapte verdwijnt met de nieuwe WAO, dan verdwijnt ook de legitimatie voor de UWVmonitor.

De monitor van het CBS is gekoppeld aan de afname van de EBB. Dit heeft als beperking dat de informatie gebaseerd is op een steekproef van de bevolking. Deze gegevens worden vervolgens geëxtrapoleerd naar de landelijke populatie en hebben altijd een bepaalde mate van onzekerheid. De EBB werkt op basis van een enquête en is niet gekoppeld aan de registraties van UWV. De wijze van bevraging sluit inhoudelijk wel aan bij de bedoeling van het wettelijk begrip van arbeidsgehandicapte maar het arbeidsgehandicaptzijn wordt niet op formele maar op inhoudelijke gronden bepaald. Het nadeel is dat een persoon die in de EBB aangeeft dat hij arbeidsgehandicapt is, dat volgens de formele definitie niet behoeft te zijn, terwijl iemand die formeel arbeidsgehandicapt is, zich niet als zodanig opstelt tijdens de enquête. Een belangrijk voordeel van de CBS-monitor is dat de CBS-monitor relatief onafhankelijk is van wijzigingen in wet- en regelgeving. Bo- 
vendien bestaat er de mogelijkheid tot internationale vergelijking waar Eurostat nu mee bezig is.

\section{Discrepanties tussen CBS- en UWV-monitor}

Een eerste zeer globale vergelijking geef weliswaar aan dat beide monitoren vergelijkbare totaalcijfers geven over het aantal arbeidsgehandicapten. Nadere vergelijking van de resultaten geeft echter aan dat er discrepanties optreden tussen beide monitoren. Zo constateert de UWV-monitor over 2001 dat 456 duizend arbeidsgehandicapten werkzaam zijn. Het CBS komt tot een beduidend hogere arbeidsparticipatie namelijk tot 778 duizend. UWV raamt het aantal niet-participerende arbeidsgehandicapten 86 duizend hoger dan het CBS, namelijk 778 duizend om 734 duizend (dit getal is inclusief 43 duizend werklozen). Dit zijn verschillen die nader onderzoek vereisen. Aangezien ook niet-werkenden in de beroepsbevolking tot de doelgroep van de EBB behoren is het aannemelijk dat het CBS juist meer niet-werkende arbeidsgehandicapten behoort te tellen. Mogelijk leidt in de toekomst een koppeling van beide gegevensbronnen via het Sociaal Statistisch Bestand ${ }^{8}$ van het CBS tot nader inzicht in de oorzaken van deze discrepantie tussen beide bronnen.

Met de komst van de arbeidsgehandicaptenmonitor van het CBS is het mogelijk geworden om effecten van het beleid op de arbeidsparticipatie van arbeidsgehandicapten c.q. chronisch zieken nu en in de toekomst op 'systeem-onafhankelijke' wijze en met hoge actualiteit te monitoren. Het kan een instrument zijn om bijvoorbeeld de werkzaamheden van de Commissie Werkend Perspectief te ondersteunen bij haar pogingen de arbeidsparticipatie van chronisch zieken te bevorderen. (De commissie 'Het Werkend Perspectief' is per 31 maart 2003 de opvolger van de Commissie Psychische Arbeidsongeschiktheid en de Commissie Arbeidsgehandicapten en Werk. De commissie heeft tot taak de reïntegratie van arbeidsgehandicapten en chronisch zieken te bevorderen en bij te dragen aan het terugdringen van het ziekteverzuim en de WAO-instroom.)

\section{Literatuur}

1. Wevers CWJ, Besseling JJM, Vos EL de. De REAliteit; integrale evaluatie van de Wet Rea. Doetinchem: Elsevier, 2001.

2. Databank StatLine in www.cbs.nl (zie kader).

3. Beckers I, Besseling JJM, Smits A. Arbeidsgehandicaptenmonitor 2002. Den Haag: Elsevier Uitgeverij, in druk.

4. Zwinkels WS, Besseling JJM. Werkhervatting van de cliënt in de WW. Den Haag: VUGA, 1997.

5. Besseling JJM, Olde C de. Emancipatie-effectrapportage Commissie Donner. Werkdocument Ministerie van SZW. Den Haag: SZW, 2002.

6. Smit AA, Andriessen S. Weer op de rails; handreiking duurzame arbeidsinpassing van langdurig werklozen. Hoofddorp: TNO Arbeid, 2003.

7. UWV. Jaaroverzicht Arbeidsgehandicapten 2001. Amsterdam: UWV, 2003.

8. Arts K, Bakker B. Dynamiek op de arbeidsmarkt; gegevens over stromen uit het Sociaal Statistisch Bestand. Paper t.b.v. conferentie 'De virtuele volkstelling en SSB' op 11 november 2003.

Personalia

Jan Besseling en Frans Verboon werken als onderzoeker bij TNO Arbeid.

Correspondentieadres

J.J.M. Besseling, T25, TNO Arbeid, Postbus 718, 2130

AS Hoofddorp.

E-mail: j.besseling@arbeid.tno.nl

\section{NIEUWS}

\section{Onderzoek Arbeidsinspectie in textielsector: $74 \%$ van bezochte bedrijven overtreedt Arbowet}

De Arbeidsinspectie heeft bij 74\% van 123 bezochte bedrijven in de textielsector één of meerdere overtredingen van de Arbeidsomstandighedenwet geconstateerd. In vier bedrijven waren de overtredingen zo ernstig dat het werk direct is stilgelegd. Daarbij ging het steeds om onveilige machines.

Dat blijkt uit het 'Projectverslag Textiel 2002'. Voor het project is circa $14 \%$ van de bedrijven in de textielindustrie bezocht. De sector scoort met genoemde $74 \%$ slecht vergeleken met het landelijk gemiddelde van 58\% voor de totale industrie in 2002 .

Aandacht voor lichamelijke belasting in de textiel blijft noodzakelijk. De Arbeidsinspectie baseert deze conclusie op de relatief grote kans op instroom in de WAO door lichamelijke belasting. Voorts beschikten negentien van de 123 bezochte bedrijven (15\%) niet over een verplichte risicoinventarisatie en -evaluatie.

Bron: Ministerie SZW, 2 februari 2004 